\title{
Tri-Band Fractal Patch Antenna for GSM and Satellite Communication Systems
}

\author{
Saad Hassan Kiani, Shahryar Shafique Qureshi, Khalid Mahmood, Mehr-e- Munir, Sajid Nawaz Khan \\ Electrical Engineering Department, Iqra National University, Peshawar, Pakistan
}

\begin{abstract}
Due to their smaller size and light weighted structures patch antennas are accustomed in modern communication Technology. With additional size in reduction, micro strip antennas are commonly used in handsets, GPS receivers etc. This paper presents a novel design of fractal shape patch antenna using U-slot on patch and defected ground structure. Due to slots on patch and ground, tri-band resonating response is attained with maximum gain and directivity of 4.22 $\mathrm{dB}$ and 6.51dBi showing high impedance bandwidth and radiation efficiency. The antenna showed good VSWR of 1.63 to 1.02 thus, showing high efficiency. As evident in the simulation results, the proposed antenna has been found useful for W-LAN, GSM, Radio Satellite, Fixed Satellite Services (RSS) \& (FSS) and satellite communication systems.
\end{abstract} VSWR

Keywords-miniaturization; directivity; gain; slots; Bandwidth;

\section{INTRODUCTION}

The increasing demand of wireless communication and multimedia services has resulted in growing efforts of designing and accomplishment of micro strip patch structures due their cost efficiency and small size. Applications of such antennas comprise but not restricted to personal communication systems, military applications, jets aircrafts and much more. One of the most necessarily antenna application is in wireless communication. In contrast with classical antennas, patch antennas offer several advantages such as ease in fabrication, low cost light weighted structures. Several techniques have been proposed to reduce the patch antenna size but at the cost of lower gain, lower directivity and reduced bandwidth. Some of the techniques are mentioned below.

With use of split ring resonators, size reduction was only up to 10 to $15 \%$ [1-2]. In [3], the dimensions of an antenna are miniaturaized to a significant level but gain and the bandwidth is also decreased. By increasing electric permittivity of a substrate, antenna size can be reduced significantly but increase of surface waves in substrate can result in declination of radiation pattern hence worsening antenna bandwidth [4]. Meta materials reduced antenna size when inserted in ground plane structure but the cost surges a bit higher [5-6]. Use of synthetic magnetic conductors resulted with lowered gain at desired resonant frequencies [7]. Hence in simple words patch size reduction has been a very common interesting topic among researchers [8-11].

Therefore, in this paper we have proposed a miniaturized fractal shape patch antenna with u-slots on patch and defected ground structure with good impedance bandwidth, gain and directivity. The proposed antenna is showing multi frequency response which can be used for various applications systems.

\section{ANTENNA DESIGN}

The basic patch antenna consists of patch, substrate and ground plane. The basic patch antenna with coaxial probe feed (contacting) is given in fig 1 .

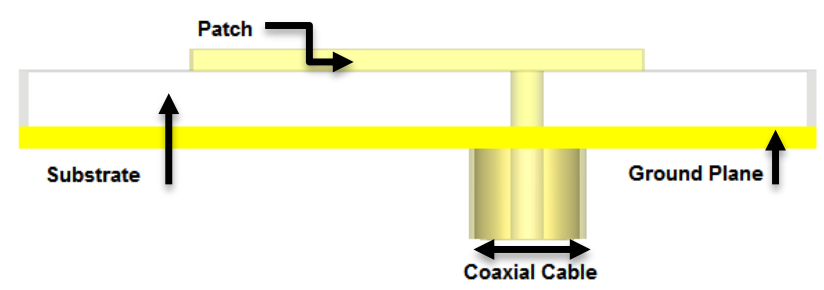

Fig. 1. Normal patch antenna

\section{A. Substrate}

The first important task while designing an antenna is selection of a proper substrate with proper dielectric constant.

In proposed antenna design, due its cost effectiveness, moisture withstanding capabilities, FR4 (lossy) is chosen as substrate with dielectric constant of 4.3 .

B. Width

In order to derive Patch width, following equation is used. (1).

$$
W=\frac{c}{2 f_{0} \sqrt{\frac{(\varepsilon r+1)}{2}}}
$$

Whereas $\mathrm{c}$ is the speed of light in free space and $f_{0}$ is the resounding frequency and $\boldsymbol{\varepsilon r}$ is the relative permittivity.

\section{Length} (2).

In order to derive Patch length, following equation is used.

Where

$$
L=L(e f f)-2 \Delta L
$$

$$
L(e f f)=\frac{c}{2 f_{0 \sqrt{\varepsilon_{(r e f f)}}}}
$$

And

$$
\varepsilon_{(r e f f)}=\frac{\varepsilon r+1}{2}+\frac{\varepsilon r-1}{4}\left(1+\frac{12 h}{W}\right)^{-1 / 2}
$$


Where $\mathrm{h}$ is the height and $\mathrm{W}$ as mention above is the patch width. Antenna with resonating frequency of $4.5 \mathrm{GHz}$ is designed by calculating patch dimensions.

Various dimensions of the proposed antenna technique are provided in table 1 .

TABLE I. DIMENSIONS OF PROPOSED ANTENNA

\begin{tabular}{|l|l|}
\hline Parameters & Values in MM \\
\hline Patch Length, PL & 16.11 \\
\hline Patch Width, PW & 21.43 \\
\hline Ground Length, GL & 28.11 \\
\hline Ground Width, GW & 33.43 \\
\hline $\begin{array}{l}\text { Vertical Fractal Slot Length, } \\
\text { VFSL }\end{array}$ & 10.0 \\
\hline $\begin{array}{l}\text { Vertical Fractal Slot Width, } \\
\text { VFSW }\end{array}$ & 4.0 \\
\hline $\begin{array}{l}\text { Horizontal Fractal Slot Length } \\
\text { HFSL }\end{array}$ & 8.0 \\
\hline $\begin{array}{l}\text { Horizontal Fractal Slot Width, } \\
\text { HFSW }\end{array}$ & 4.0 \\
\hline U Slot Length, UL & 6.0 \\
\hline U Slot Width, UW & 1.0 \\
\hline Patch Height, PH & 0.0035 \\
\hline Height of Ground, HG & 0.08 \\
\hline Height of Substrate, HS & 2.0 \\
\hline $\begin{array}{l}\text { Horizontal U and H Slot } \\
\text { Width, HUW\&HHW }\end{array}$ & 1.0 \\
\hline Horizontal U Slot Length, HUL & 8.0 \\
\hline Horizontal H Slot Length, HHL & 7.0 \\
\hline $\begin{array}{l}\text { Vertical U and H Slot Length, } \\
\text { VUL\&VHL }\end{array}$ & 6.0 \\
\hline $\begin{array}{l}\text { Vertical U and H Slot Width, } \\
\text { VUW \&VHW }\end{array}$ & 1.0 \\
\hline
\end{tabular}

After designing patch antenna for $4.5 \mathrm{GHz}$, fractal shape is implemented as following.

Patch is slotted by $8 \mathrm{~mm}$ length and $10 \mathrm{~mm}$ width horizontally and $10 \mathrm{~mm}$ length and $4 \mathrm{~mm}$ width vertically. $\mathrm{U}$ shape slot on fractal patch is designed with the following dimensions as shown in Fig 2.

Length of slot is $6 \mathrm{~mm}$ and width of the slot is $1 \mathrm{~mm}$. Now to further reduce size and for efficient frequency response defected ground structure technique is used by adding $U$ and $\mathrm{H}$ slot on a ground plane as shown in fig 2 and figure 3 .

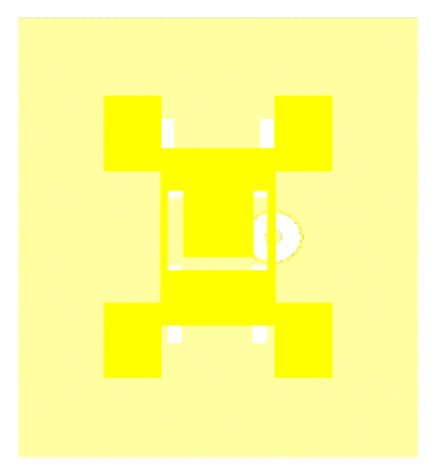

Fig. 2. Frontal View of Patch

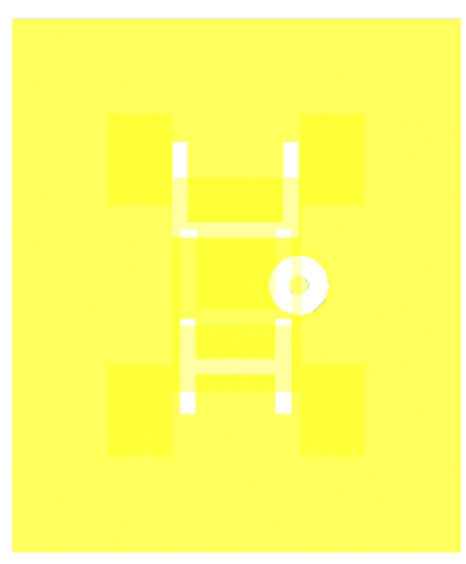

Fig. 3. Frontal View of Ground

The antenna is fed by Co-axial cable a contacting scheme in which inner conductor is mounded to patch through hole from ground through substrate while outer conductor connected with ground plane.

\section{RESULTS AND DISSCUSSIONS}

After simulation, we got the following results in Return loss graph. 


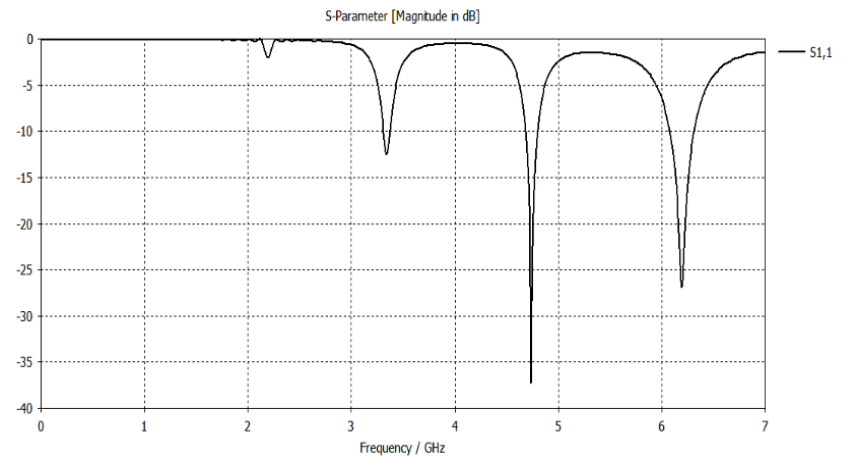

Fig. 4. Return loss graph of antenna

From taking a look at return loss graph shown in Fig 4, we clearly see that we have got a multi frequency response with very good return loss. For frequency 3.349 we have got $12.05 \mathrm{~dB}$ return loss, $2.92 \mathrm{~dB}$ of gain $5.64 \mathrm{dBi}$ directivity and 60 MHZ of bandwidth.

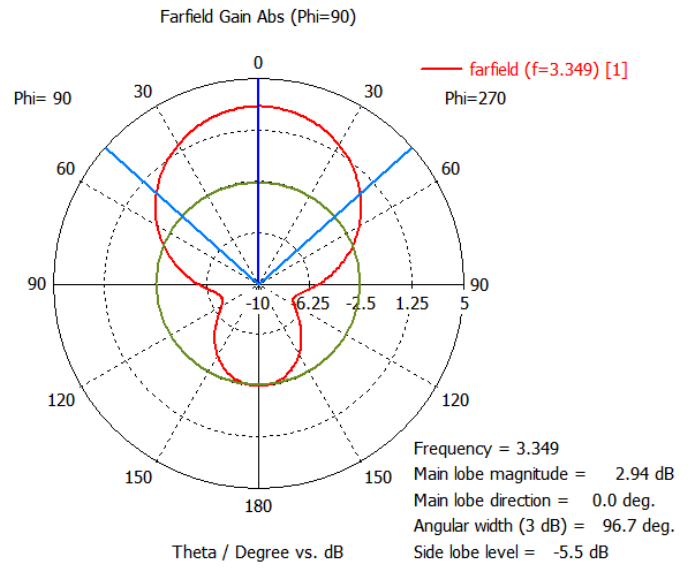

Fig. 5. 1D plot of Gain at $3.349 \mathrm{GHz}$ frequency

In $3.349 \mathrm{GHz}$ gain plot, the main front lobe scale is $2.91 \mathrm{~dB}$, main front lobe direction is 0 degrees and angular width is 96.8 degrees while back lobe scale is $-5.5 \mathrm{~dB}$.

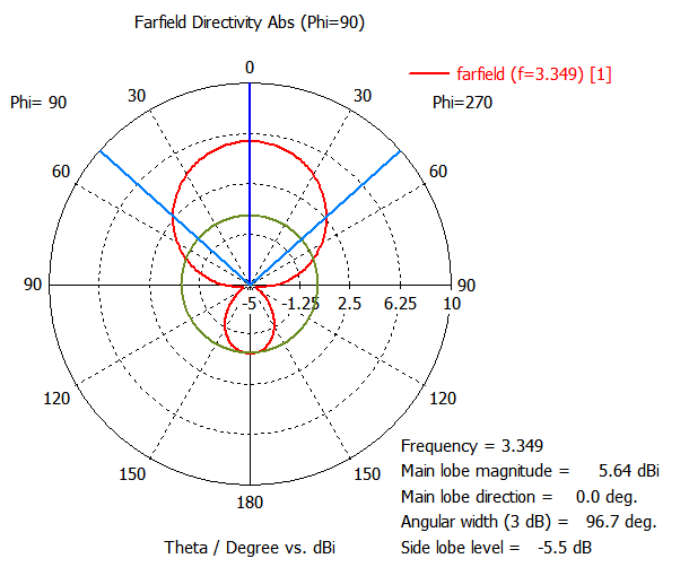

Fig. 6. 1D plot of Directivity at $3.349 \mathrm{GHz}$ frequency

In $3.349 \mathrm{GHz}$ directivity plot, the main front lobe scale is $5.64 \mathrm{dBi}$, main lobe direction is 0.0 degrees and angular width is 96.8 degrees while back lobe scale is $-5.5 \mathrm{~dB}$.

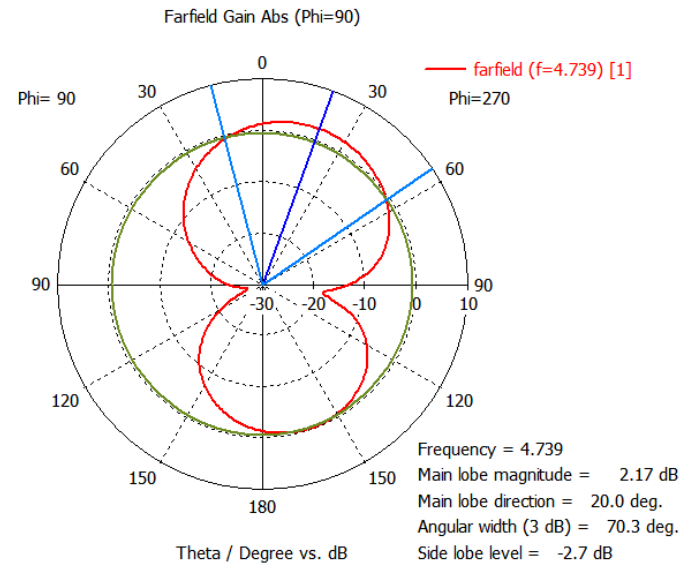

Fig. 7. 1D plot of Gain at $4.739 \mathrm{GHz}$ frequency

In $4.739 \mathrm{GHz}$ gain plot, the main front lobe scale is $2.17 \mathrm{~dB}$, main lobe direction is 20.0 degrees and angular width is 70.4 degrees while back lobe scale is $-2.7 \mathrm{~dB}$.

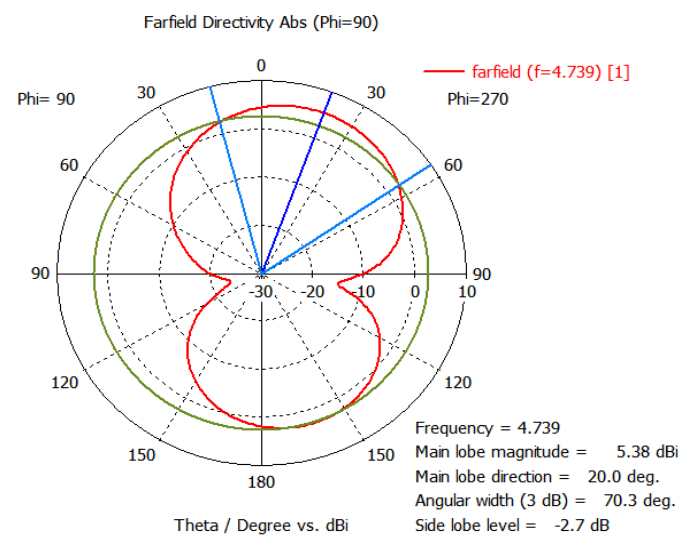

Fig. 8. 1D plot of Directivity at $4.739 \mathrm{GHz}$ frequency

In $4.739 \mathrm{GHz}$ directivity plot, the main front lobe scale is $5.38 \mathrm{dBi}$, main front lobe direction is 20.0 degrees and angular width is 70.4 degrees while back lobe scale is $-2.7 \mathrm{~dB}$.

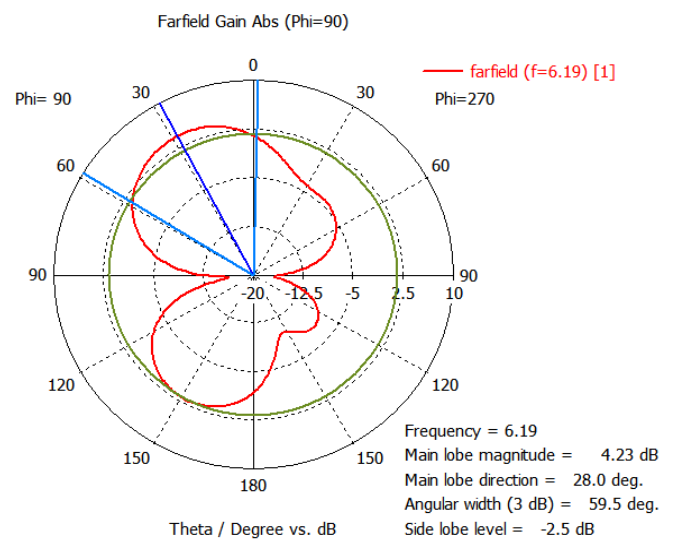

Fig. 9. 1D plot of Gain at $6.19 \mathrm{GHz}$ frequency

In $6.19 \mathrm{GHz}$ gain plot, the main front lobe scale is $4.22 \mathrm{~dB}$, main front lobe direction is 28.0 degrees and angular width is 59.2 degrees while back lobe scale is $-2.5 \mathrm{~dB}$. 


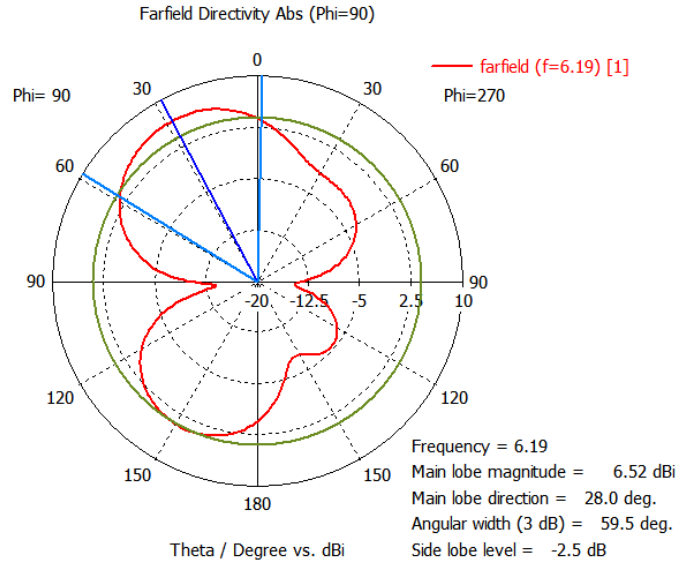

Fig. 10. 1D plot of directivity at $6.19 \mathrm{GHz}$ frequency

In $6.19 \mathrm{GHz}$ directivity plot, the main front lobe magnitude is $6.51 \mathrm{dBi}$, main front lobe direction is 28.0 degrees and angular width is 59.2 degrees while back lobe scale is $-2.5 \mathrm{~dB}$.

As goes for VSWR it showed satisfactory results clearly evident from figure 11 as all the resonant frequencies showed response less than $2 \mathrm{~dB}$ which shows the antenna is efficient as 96 to $98 \%$.

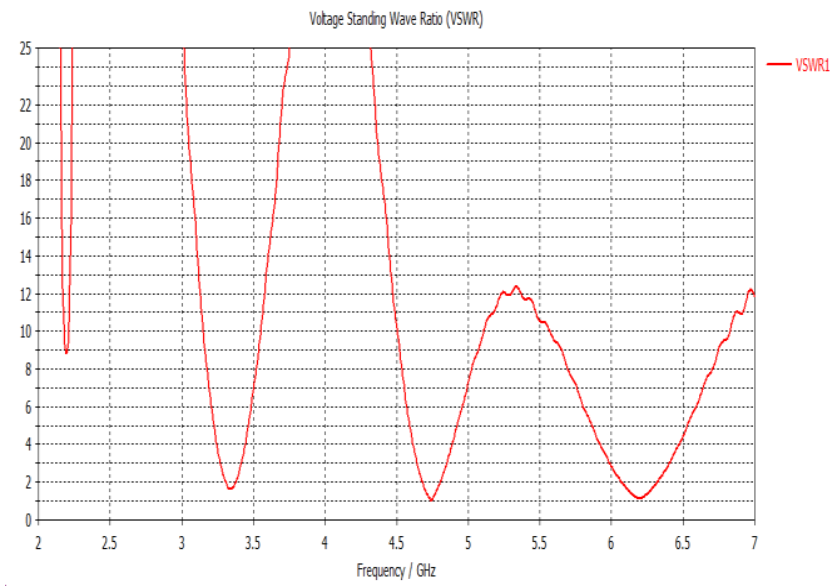

Fig. 11. Voltage Standing Wave Ratio Graph of Antenna

The approximate values of VSWR of the proposed antenna are shown in the following table.

TABLE II. VSWR VALUES OF RESONANT FREQUENCIES

\begin{tabular}{|l|l|l|l|l|l|}
\hline $\begin{array}{l}\text { Resonant } \\
\text { Frequency }\end{array}$ & VSWR & $\begin{array}{l}\text { Reflection } \\
\text { Coefficient }\end{array}$ & $\begin{array}{l}\text { Reflected } \\
\text { Power } \\
(\%)\end{array}$ & $\begin{array}{l}\text { Reflected } \\
\text { Power } \\
\text { (dB) }\end{array}$ & $\begin{array}{l}\text { Mismatch } \\
\text { Loss (dB) }\end{array}$ \\
\hline $3.3 \mathrm{GHz}$ & 1.63 & 0.24 & 5.7 & -12.41 & 0.26 \\
\hline $4.7 \mathrm{GHz}$ & 1.02 & 0.01 & 0.0 & -40.09 & 0.00 \\
\hline $6.1 \mathrm{GHz}$ & 1.10 & 0.05 & 0.2 & -26.44 & 0.01 \\
\hline
\end{tabular}

From results shown in table 2 all the resonant frequencies prove that antenna impedance is matched. For $3.3 \mathrm{GHz}$ antenna power delivered is up to $94.3 \%$. For $4.7 \mathrm{GHz}$ nearly all the power is delivered from transmitter side. And at last for
$6.1 \mathrm{GHz}$ power radiated is nearly $99.98 \%$.

The results attained from resonating frequencies both gain and directivity are better than [12-13]. For resonant frequency of $3.3 \mathrm{GHz}$ there are no side lob radiations and with the gain exceeding $2 \mathrm{~dB}$, makes it suitable for GSM and LTE applications. For $4.7 \mathrm{GHz}$ frequency although with slight increase in back radiation, with the higher gain and return loss of resonant frequency it becomes suitable for vehicular and $\mathrm{S}$ band communication applications. At last for $6.1 \mathrm{GHz}$ the radiation pattern achieved was very interesting as it was in The form of butterfly. But with the side lob level of $2.5 \mathrm{~dB}$ this antenna proves significant response of it making it suitable for Fixed Satellite Services (Earth to Space) applications.

The following table shows all the parameters results of the resonant frequencies of proposed antenna.

TABLE III. PARAMETER RESUlTS

\begin{tabular}{|l|l|l|l|l|}
\hline $\begin{array}{l}\text { Resonant } \\
\text { Frequency }\end{array}$ & $\begin{array}{l}\text { Return } \\
\text { Loss }\end{array}$ & Gain & Bandwidth & Directivity \\
\hline $3.3 \mathrm{GHz}$ & $-12.36 \mathrm{~dB}$ & $2.91 \mathrm{~dB}$ & $60 \mathrm{MHz}$ & $5.64 \mathrm{dBi}$ \\
\hline $4.7 \mathrm{GHz}$ & $-37.43 \mathrm{~dB}$ & $2.17 \mathrm{~dB}$ & $110 \mathrm{MHz}$ & $5.38 \mathrm{dBi}$ \\
\hline $6.1 \mathrm{GHz}$ & $-26.10 \mathrm{~dB}$ & $4.22 \mathrm{~dB}$ & $300 \mathrm{MHz}$ & $6.51 \mathrm{dBi}$ \\
\hline
\end{tabular}

The dimensions of conventional patch antenna with the central resounding frequency of $3.346 \mathrm{GHz}$ would require dimensions of $27.94 \times 21.00=585 \mathrm{~mm}^{2}$ while as for proposed design, only by dimensions of $16 \times 21=361 \mathrm{~mm}^{2}$ it is achieved, resulting in shrinking the size up to $61.70 \%$, which is more significant than formerly published methodologies. Also the antenna is showing triple band frequency response with good gain, directivity and good bandwidth for resonant frequencies [12-13].

\section{CONCLUSION}

In this paper, a new methodology with tri band resonating frequency is presented. Antenna with size reduction of $61.70 \%$ is obtained using defected ground structure and U-Shaped slot on the fractal shape patch. As a result antenna produced responded with a high gain, directivity and good impedance bandwidth for each resonant frequency. The proposed antenna is highly efficient as for all resonating frequencies, the VSWR is seen to be less than 2 . The proposed antenna is very useful and can be used for W-LAN, GSM, Radio Satellite, Fixed Satellite Services (RSS) \& (FSS) and Satellite communication system applications.

\section{FUTURE SCOPE}

The proposed tri band antenna can be implemented via MIMO technique and also as in terms of stack configuration. Using stack configuration, further miniaturization can be expected.

\section{ACKNOWLEDGEMENT}

The authors would acknowledge the environment and support provided by Iqra National University Peshawar, Pakistan. 


\section{REFERENCES}

[1] Kärkkäinen, Mikko, and Pekka Ikonen. "Patch antenna with stacked split-ring resonators as an artificial magneto-dielectric substrate." Microwave and Optical Technology Letters 46.6 (2005): 554-556.

[2] Dong, Yuandan, Hiroshi Toyao, and Tatsuo Itoh. "Design and characterization of miniaturized patch antennas loaded with complementary split-ring resonators." IEEE Transactions on Antennas and Propagation 60.2 (2012): 772-785.

[3] Mosallaei, Hossein, and Kamal Sarabandi. "Antenna miniaturization and bandwidth enhancement using a reactive impedance substrate." IEEE Transactions on Antennas and Propagation 52.9 (2004): 2403-2414.

[4] Yuan, Bo, et al. "An axial-ratio beamwidth enhancement of patch antenna with digonal slot and square ring." Microwave and Optical Technology Letters 58.3 (2016): 672-675.

[5] Singhal, P. K., Bimal Garg, and Nitin Agrawal. "A high gain rectangular microstrip patch antenna using 'different c patterns' metamaterial design in L-band." Advanced Computational Techniques in Electromagnetics 2012 (2012): 1-5.

[6] Dong, Yuandan, and Tatsuo Itoh. "Metamaterial-based antennas." Proceedings of the IEEE 100.7 (2012): 2271-2285.

[7] Rahmadani and A. Munir, "Microstrip patch antenna miniaturization using artificial magnetic conductor," in Telecommunication Systems, Services, and Applications (TSSA), 2011 6th International Conference on, 2011, pp. 219-223.
[8] Abed, A.T. and Singh, M.S.J., 2016. Slot antenna single layer fed by step impedance strip line for $\mathrm{Wi}-\mathrm{Fi}$ and Wi-Max applications. Electronics Letters.

[9] Hasan, Mohammed, et al. "A novel miniaturized triple-band antenna." Electrical \& Computer Engineering (ICECE), 2012 7th International Conference on. IEEE, 2012/

[10] Yassen, M. T., Hussan, M. R., Hammas, H. A., \& Ali, J. K. (2016). A Compact Dual-band Antenna with Fractal Slot Annular Ring and Defected Ground Structure.

[11] Maiti, Satyabrata, Naikatmana Pani, and Amrit Mukherjee. "Modal analysis and design a planar elliptical shaped UWB antenna with triple band notch characteristics." Signal Propagation and Computer Technology (ICSPCT), 2014 International Conference on. IEEE, 2014.

[12] Farooq U. Multiband microstrip patch antenna using DGS for L-Band, S-Band, C-Band \& mobile applications. In2016 13th International Conference on Modern Problems of Radio Engineering, Telecommunications and Computer Science (TCSET) 2016 Feb 23 (pp. 198-201). IEEE.

[13] Saad Hassan Kiani, Khalid Mahmood, Sharyar Shafeeq, Mehre Munir and Khalil Muhammad Khan, "A Novel Design of Miniaturaized Patch Antenna Using Different Substrates for S-Band and C-Band Applications" International Journal of Advanced Computer Science and Applications(IJACSA), 7(7), 2016. 